\title{
OXIDAÇÃO DE OXITETRACICLINA PELO PROCESSO FENTON: ESTUDO PARAMÉTRICO DA TEMPERATURA, CONCENTRAÇÃO INICIAL DE PERÓXIDO DE HIDROGÊNIO E DE ÍON FERROSO
}

\author{
R. M. MIYAGUTI, M. S. A. PALMA \\ Universidade de São Paulo, Departamento de Tecnologia Bioquímico-Farmacêutica \\ E-mail para contato: msapalma@usp.br
}

\begin{abstract}
RESUMO - A oxitetraciclina é um antibiótico da família das tetraciclinas, de amplo espectro, presente em efluentes industriais, domésticos e provenientes de áreas rurais. Seu principal inconveniente no meio ambiente é a potencialização do surgimento de bactérias resistentes. Neste trabalho foi estudada a degradação da oxitetraciclina, um antibiótico amplamente fabricado para consumo humano, através do processo Fenton de acordo com um planejamento experimental do tipo DCCR. Foram estudadas a influência da temperatura $\left(T=0\right.$ a $\left.40^{\circ} \mathrm{C}\right)$, concentração de íons ferrosos $\left(C_{F e 2+}=5\right.$ a $\left.120 \mathrm{mg} / \mathrm{L}\right)$ e concentração de peróxido de hidrogênio $\left(C_{\mathrm{H} 2 \mathrm{O} 2}=100\right.$ a $\left.900 \mathrm{mg} / \mathrm{L}\right)$ na concentração residual final de oxitetraciclina $\left(C_{\text {Oxi,Res,Final }}\right)$, sendo determinada a melhor condição operacional $\left(T=40^{\circ} \mathrm{C}, C_{H 2 O 2}=500 \mathrm{mg} / \mathrm{L}, C_{F e 2+}=62,5 \mathrm{mg} / \mathrm{L}\right)$ para as quais $C_{\text {Oxi,Res, Final }}=$ $2,6 \mathrm{mg} / \mathrm{L}$. O estudo paramétrico mostrou que $C_{\text {Oxi,Res,Final }}$ foi pouco influenciada por $C_{\mathrm{Fe} 2+}$, $C_{\mathrm{H} 2 \mathrm{O} 2}$ e $T$ nas faixas de valores estudadas. Para $35 \leq C_{\mathrm{Fe} 2+} \leq 120 \mathrm{mg} / \mathrm{L}$ o valor médio de $C_{\text {Oxi,Res,Final }}$ foi de $2,7 \mathrm{mg} / \mathrm{L}$; para $300 \leq C_{H_{2} O 2} \leq 700 \mathrm{mg} / \mathrm{L}$ o valor médio de $C_{\text {Oxi,Res,Final }}$ foi de $2,2 \mathrm{mg} / \mathrm{L} ; C_{\text {Oxi,Res,Final }}=6,5 \mathrm{mg} / \mathrm{L}$ é um máximo para $T=20^{\circ} \mathrm{C}$. O menor valor de concentração residual da Oxitetraciclina $\left(C_{\text {Oxi,Res,Final }}=0,9 \mathrm{mg} / \mathrm{L}\right)$ foi obtida para $T=$ $50^{\circ} \mathrm{C}, C_{\mathrm{H}_{2 O 2}}=500 \mathrm{mg} / \mathrm{L}$ e $C_{\mathrm{Fe} 2+}=62,5 \mathrm{mg} / \mathrm{L}$. O processo Fenton utilizado no tratamento da oxitetraciclina mostrou ser rápido, reprodutível e eficiente.
\end{abstract}

\section{INTRODUÇÃO}

Os fármacos são sintetizados para funções fisiológicas específicas, portanto, a presença dessas substâncias no ambiente pode causar efeitos indesejados em outros organismos (Kümmerer, 2009), tais como inibição da reprodução (Park e Choi, 2008) ou disfunção endócrina (Fent et al 2006; Ji et al. 2010; Ji et al., 2012). Enquanto o uso de antibióticos veterinários como aditivos foi proibido em algumas partes do mundo, uma quantidade significativa de tais medicamentos ainda está sendo usada como promotor de crescimento em todo o mundo. As tetraciclinas estão entre os antibióticos mais utilizados tanto na medicina veterinária quanto na medicina humana (Borghi e Palma, 2014). Antibióticos foram detectados em meio aquático, incluindo as águas de superfície em concentrações que variam de $\mathrm{ng} / \mathrm{L} \mathrm{a} \mu \mathrm{g} / \mathrm{L}$. A oxitetraciclina e a eritromicina foram detectados em águas de superfície em concentrações elevadas quanto 2,20 $\mu \mathrm{g} / \mathrm{L}$ na China (Wei et al., 2010) e 1,70 $\mu \mathrm{g} / \mathrm{L}$ na Alemanha 


\section{9 a 22 de outubro de 2014 \\ Florianópolis/SC}

(Hirsch et al., 1998). Os fármacos de uso humano atingem o meio ambiente provenientes da rede esgoto e porque eles não são adequadamente tratados em Estações de Tratamento de Esgotos municipais, visto que estas estações não foram projetadas para tratamento de fármacos (Bila e Dezotti, 2003; Li et al., 2008; Aga, 2008).

Os processos que têm mostrado maior eficiência de degradação de moléculas orgânicas complexas, como os fármacos, são os Processos Oxidativos Avançados (POAs). Nestes processos as reações de degradação envolvem espécies transitórias oxidantes, como os radicais hidroxila (Martins et al., 2011) que dependendo das condições operacionais e das moléculas a serem degradadas, podem ocasionar a mineralização completa ou parcial das moléculas orgânicas que compõem os antibióticos, gerando uma carga de resíduos muito menor ou nula em relação aos processos não destrutivos.

O processo Fenton é um POA que consiste na degradação de produtos através da dissociação do peróxido de hidrogênio através da reação de oxirredução do íon ferroso em meio ácido na ausência de luz (radiação UV), promovendo a formação do radical hidroxila $(\bullet \mathrm{OH})$, responsável pela quebra de moléculas orgânicas na tentativa de gerar compostos inativos biologicamente (Neyens e Bayens, 2003; Pignatello et al., 2006; Wang e Xu, 2012).

O presente trabalho tem por objetivo estudar a degradação do antibiótico oxitetraciclina através da oxidação química pelo processo Fenton, partindo-se dos resultados obtidos através de Planejamento Fatorial DCCR publicados anteriormente (Miyaguti e Palma, 2012), sendo agora apresentados os resultados do estudo paramétrico ao redor da melhor condição experimental obtida com o planejamento fatorial.

\section{MATERIAIS E MÉTODOS}

\subsection{Materiais}

Para os ensaios de degradação foram utilizados oxitetraciclina, peróxido de hidrogênio $\left(\mathrm{H}_{2} \mathrm{O}_{2}\right)$ e sulfato ferroso heptahidratado $\left(\mathrm{FeSO}_{4} \cdot 7 \mathrm{H}_{2} \mathrm{O}\right)$. Para a quantificação do fármaco foram empregados molibdato de sódio dihidratado $\left(\mathrm{Na}_{2} \mathrm{MoO}_{4} .2 \mathrm{H}_{2} \mathrm{O}\right)$, nitrato de sódio $\left(\mathrm{NaNO}_{3}\right)$ e tampão acetato $(0,01 \mathrm{M}$; pH 5,0). Para a quantificação de peróxido de hidrogênio foram utilizados ácido sulfúrico $\left(\mathrm{H}_{2} \mathrm{SO}_{4}\right)$ e permanganato de potássio $\left(\mathrm{KMnO}_{4}\right)$. Em todos os ensaios e amostragens utilizou-se água destilada, bem como para o preparo das soluções.

\subsection{Equipamentos}

Os equipamentos utilizados nos ensaios envolvendo a oxidação química de oxitetraciclina pelo processo Fenton estão mostrados na Figura 1. O béquer de vidro (A) com volume útil de $500 \mathrm{~mL}$ foi fixado em um sistema de banho-maria (B) com controle para aquecimento ou resfriamento da temperatura, agitador mecânico (C), termômetro (D) e medidor de $p H(\mathrm{E})$. 


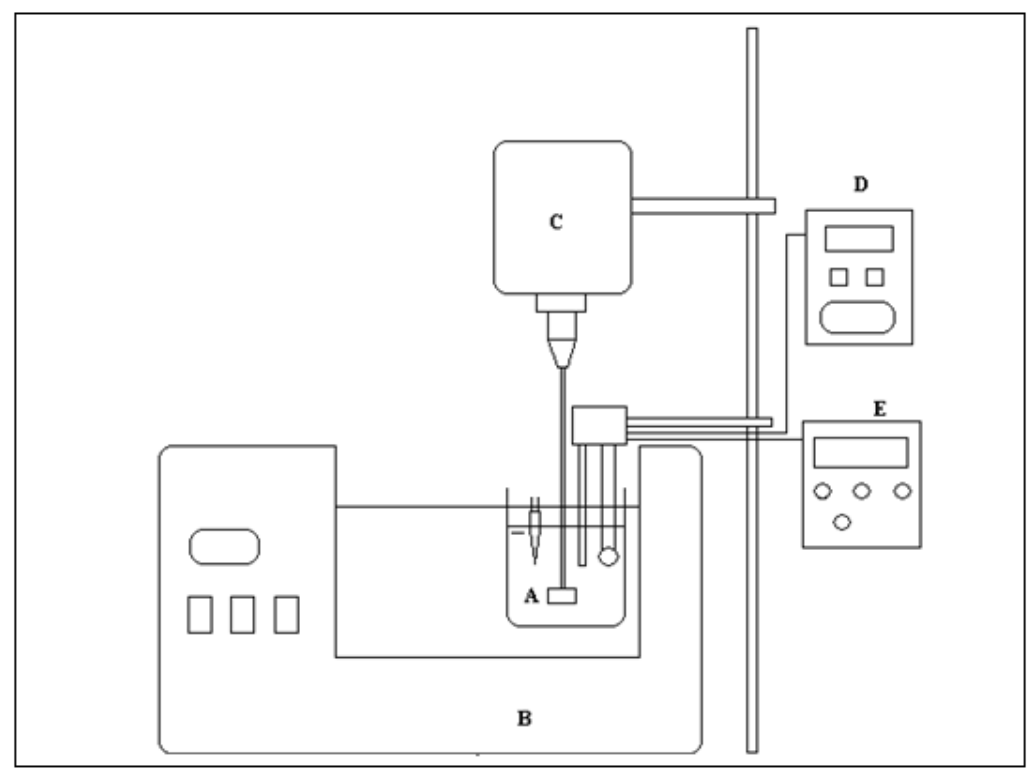

Figura 1 - Configuração dos equipamentos utilizados nos ensaios de oxidação de oxitetraciclina.

\subsection{Procedimento Experimental}

Transferia-se $200 \mathrm{~mL}$ de solução aquosa de oxitetraciclina com concentração de $100 \mathrm{mg} / \mathrm{L}$ para um béquer envolto em papel alumínio, de modo que a reação ocorresse na ausência de luz e, em seguida, o béquer era colocado em banho termostatizado com a temperatura ajustada de acordo com o planejamento experimental. Quando o conteúdo do béquer alcançava a temperatura desejada, adicionava-se o peróxido de hidrogênio e, subsequentemente, o sulfato ferroso, ambos com quantidades adequadas para que as concentrações destes reagentes no meio reacional estivessem condizentes com o os valores propostos para o ensaio. $\mathrm{O}$ ensaio iniciava-se com a adição do sulfato ferroso, quando então o cronômetro era acionado. Em tempos pré determinados, coletava-se, através de uma micropipeta, uma alíquota de $1 \mathrm{~mL}$ do meio reacional para determinação espectrofotométrica da concentração residual de oxitetraciclina e $2 \mathrm{~mL}$ para quantificação do peróxido de hidrogênio.

Os ensaios de oxidação da oxitetraciclina foram realizados em um banho termostatizado, com a temperatura, $T$, a concentração de agente oxidante, $C_{H 2 O 2}$, e de catalisador, $C_{F e 2+}$, ajustadas de acordo com o planejamento experimental do tipo Delineamento Composto Central Rotacional, DCCR (Miyaguti e Palma, 2012).

\subsection{Método Analítico}

O método desenvolvido para a análise da oxitetraciclina foi baseado no método de Stankov e Veselinovic (1988) para a análise de doxiciclina, um composto pertencente à mesma classe da oxitetraciclina: a classe das tetraciclinas. Na quantificação da oxitetraciclina, o peróxido de hidrogênio é um interferente que reage com o íon molibdato, formando um complexo amarelo, resultando em um falso incremento nos resultados. Por isso, foi necessário o uso de uma solução 


\section{9 a 22 de outubro de 2014 \\ Florianópolis/SC}

inibidora de sistema Foto Fenton, proposto por Motta (2005). Esta solução é composta de iodeto de potássio $0,1 \mathrm{M}$, sulfito de sódio $0,2 \mathrm{M}$ e hidróxido de sódio $0,1 \mathrm{M}$, em meio aquoso. Porém, com a adição da solução inibidora Foto Fenton, os íons de ferro se solubilizam podendo interferir na análise espectrofotométrica, sendo necessária a sua remoção do meio. Desta forma, antes da leitura espectrofotométrica, as amostras foram filtradas em filtros de acetato de celulose $0,45 \mu \mathrm{m}$. As concentrações de oxitetraciclina são determinadas tomando-se como base a análise do complexo formado entre o fármaco e o molibdato de sódio.

Para a análise, coletava-se em um frasco contendo $1 \mathrm{~mL}$ da solução inibidora do sistema Foto Fenton, $1 \mathrm{~mL}$ de alíquota do meio reacional. A solução era homogeneizada e filtrada em filtro de 0,45 $\mu \mathrm{m}$ acoplado a uma seringa própria, coletando o filtrado em frasco limpo. Transferia-se $1 \mathrm{~mL}$ do filtrado para um balão volumétrico de $5 \mathrm{~mL}$ e adicionava-se $1 \mathrm{~mL}$ de solução $\mathrm{Na}_{2} \mathrm{MoO}_{4}(0,005 \mathrm{M}), 0,5$ mL de $\mathrm{NaNO}_{3}(1 \mathrm{M})$ e $0,5 \mathrm{~mL}$ de solução tampão acetato $(0,01 \mathrm{M}$ e pH 5,0). $\mathrm{O}$ balão era avolumado com água destilada e a solução homogeneizada. Transferia-se a solução para cubeta de $1 \mathrm{~cm}$ e, então, era efetuada a leitura em espectrofotômetro em comprimento de onda de 390nm.

\section{RESULTADOS E DISCUSSÃO}

Os resultados dos ensaios segundo o planejamento DCCR já foram publicados anteriormente (Miyaguti e Palma, 2012) e não serão mostrados aqui. Observou-se uma grande variação nos resultados de $C_{\text {Oxi,Res,Final }}$ que variaram de 0,9 a 33,0 mg/L. O menor valor foi obtido para $T=40^{\circ} \mathrm{C}$, $C_{\mathrm{H} 2 \mathrm{O} 2}=500 \mathrm{mg} / \mathrm{L}$ e $C_{\mathrm{Fe}}{ }^{2+}=62,5 \mathrm{mg} / \mathrm{L}$. Estes resultados também mostraram que o planejamento utilizado contemplou condições operacionais que influenciaram significativamente a variável dependente.

Os resultados foram tratados com o Software Statistica ${ }^{\circledR}$ e mostraram que apenas a concentração de peróxido de hidrogênio $(\mathrm{p}<0,05)$ foi significativa. A melhor condição operacional determinada pelo planejamento fatorial foi admitida como o ponto de partida para se efetuar um estudo paramétrico das variáveis, cujas condições experimentais e resultados estão mostradas nas Figuras 2 a 4.

A Figura 2 confirma os resultados da análise de variância, ou seja, a concentração de ion ferroso não influencia o processo em termos de $C_{\text {Oxi,Res,Final }}$ Para valores de concentração de ion ferroso inferior a $35 \mathrm{mg} / \mathrm{L}$ pode ter havido geração insuficiente de radicais hidroxila. A Figura 2 mostra que para concentrações de íon ferroso entre 35 e $120 \mathrm{mg} / \mathrm{L}$, a concentração residual final de oxitetraciclina é mínima e tem o valor aproximado de $2,7 \mathrm{mg} / \mathrm{L}$. Para valores de $C_{F e}{ }^{2+}$ menores que $35 \mathrm{mg} / \mathrm{L}$ há um aumento da concentração residual final de oxitetraciclina e também foram ocasionados pela geração insuficiente de radicais hidroxila segundo a Equação 1.

$$
\mathrm{Fe}^{+2}+\mathrm{H}_{2} \mathrm{O}_{2} \rightarrow \mathrm{Fe}^{+3}+\mathrm{HO}^{\bullet}+\mathrm{HO}^{-} \quad\left(\text { iniciação da cadeia: } \mathrm{k}_{1} \approx 70 \mathrm{M}^{-1} \mathrm{~s}^{-1}\right. \text { ) }
$$




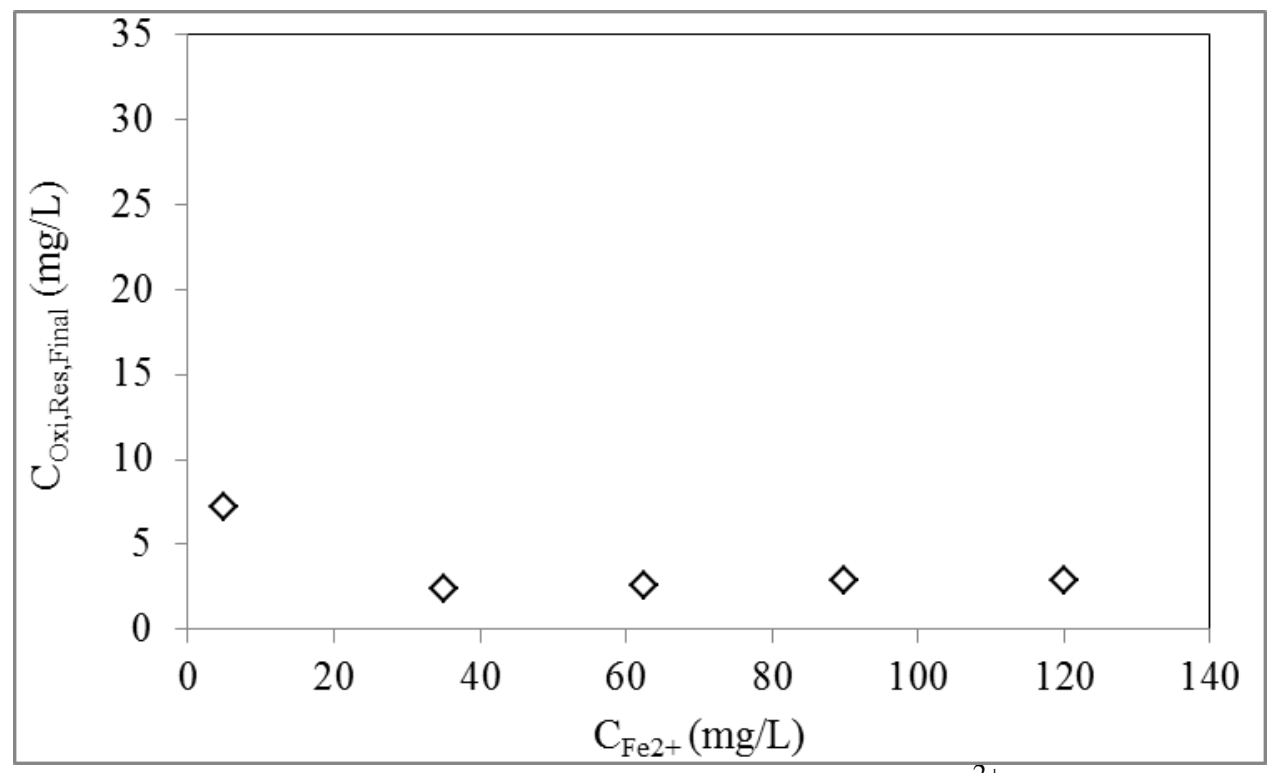

Figura 2 - Influência da concentração inicial de ion ferroso, $\mathrm{C}_{\mathrm{Fe}}{ }^{2+}$, na concentração residual final de oxitetraciclina, $\mathrm{C}_{\text {Oxi.Res,Final }}$

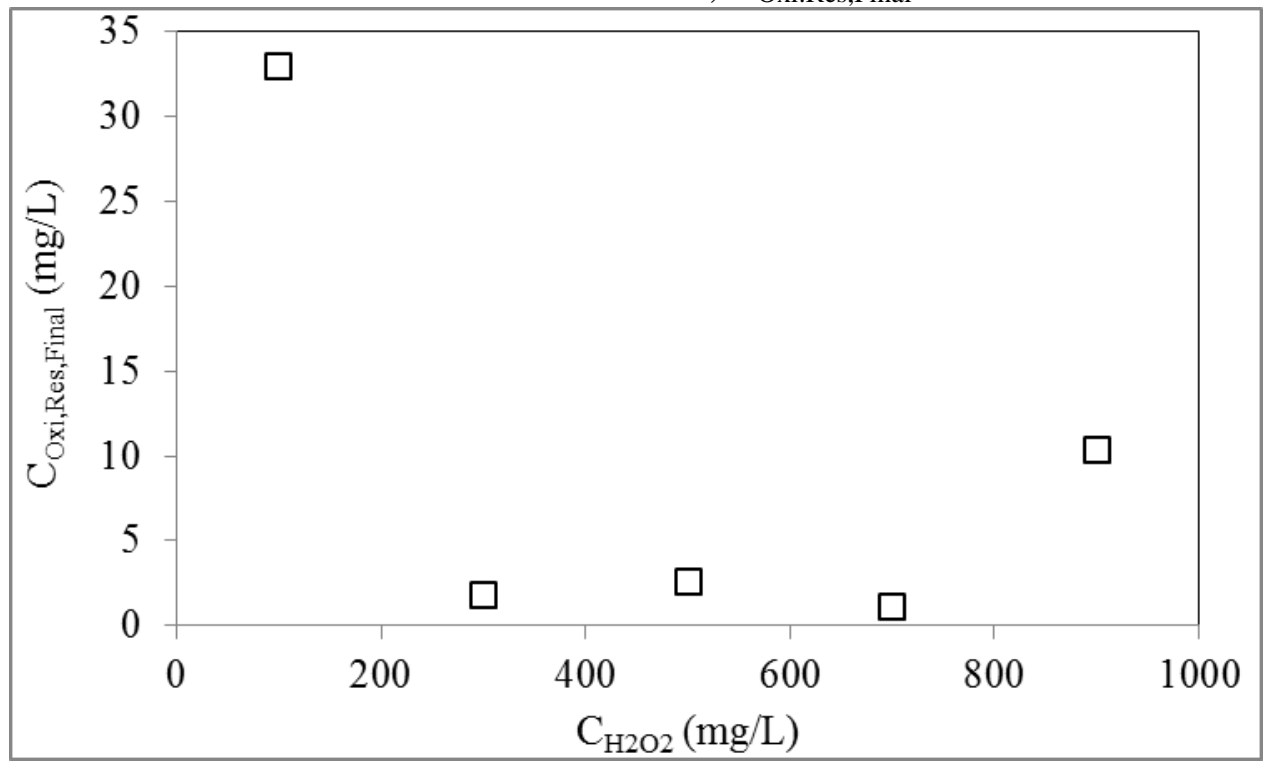

Figura 3 - Influência da concentração inicial de peróxido de hidrogênio, $\mathrm{C}_{\mathrm{H} 2 \mathrm{O} 2}$, na concentração residual final de oxitetraciclina, $\mathrm{C}_{\text {Oxi.Res,Final }}$ 


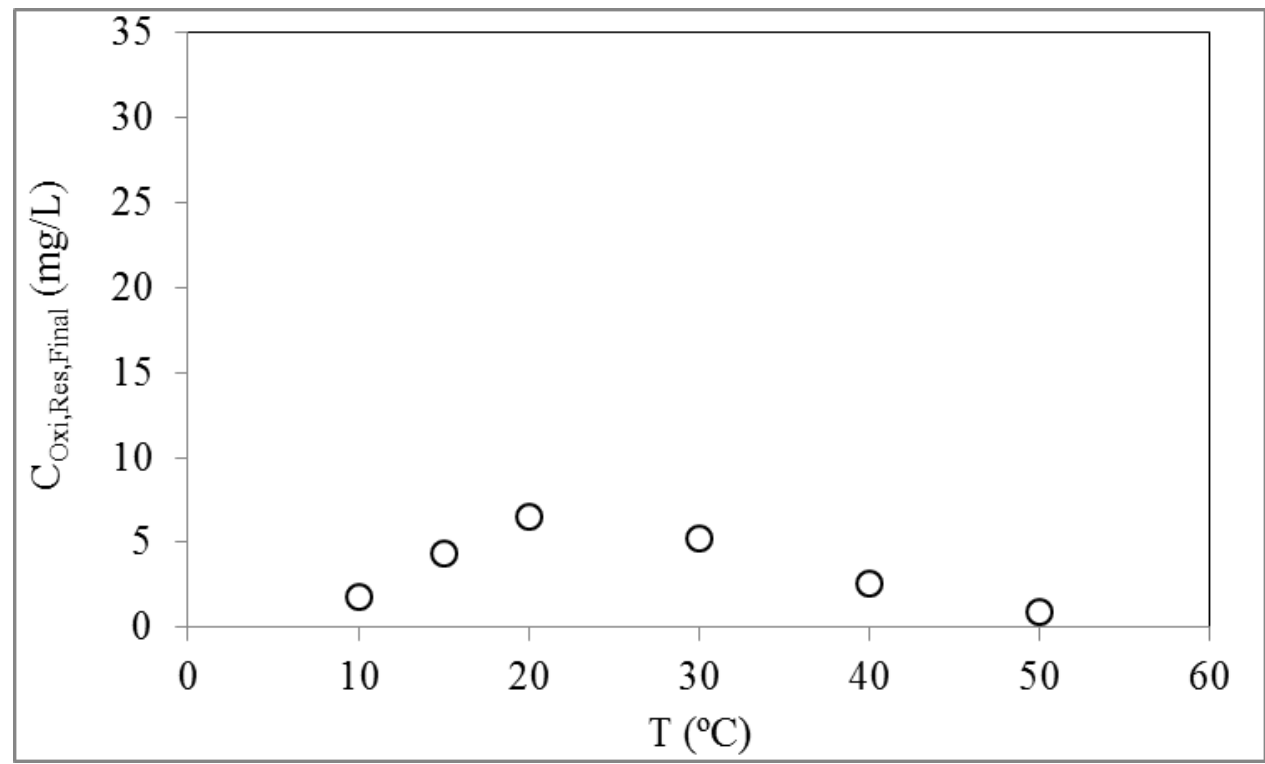

Figura 4 - Influência da temperatura, $T$, na concentração residual final de oxitetraciclina, $\mathrm{C}_{\text {Oxi.Res,Final }}$

A Figura 3 mostra que a concentração de oxitetraciclina mínima é de 2,2 $\mathrm{mg} / \mathrm{L}$ para concentrações iniciais de $\mathrm{H}_{2} \mathrm{O}_{2}$ entre 300 e $700 \mathrm{mg} / \mathrm{L}$. O maior valor de $C_{\text {Oxi,Res,Final }}(33 \mathrm{mg} / \mathrm{L})$ foi obtido para concentração inicial de peróxido $C_{H 2 O 2, \text { inicial }}=100 \mathrm{mg} / \mathrm{L}$. A baixa eficiência do ensaio com $100 \mathrm{mg} / \mathrm{L}$ de peróxido de hidrogênio pode ser atribuída à baixa disponibilidade deste para a reação com o íon ferroso, não gerando radicais hidroxila suficientes para que a degradação fosse mais eficiente. $\mathrm{O}$ aumento do valor da concentração residual final de oxitetraciclina para a concentração de peróxido $900 \mathrm{mg} / \mathrm{L}$ indica que há um excesso de peróxido de hidrogênio no meio, o que provoca uma inibição do processo, pois este pode estar atuando como sequestrante de radicais hidroxila, conforme a Equação 2. Como a constante da taxa da Equação 2, $\mathrm{k}_{2}=3,3 \cdot 10^{7} \mathrm{M}^{-1} \mathrm{~s}^{-1}$, é maior que a constante da taxa de geração de radicais hidroxila, Equação $1, \mathrm{k}_{1} \approx 70 \mathrm{M}^{-1} \mathrm{~s}^{-1}$, o sequestro de radicais hidroxila ocorrerá preferencialmente em relação à sua produção, fazendo com que a oxidação da oxitetraciclina seja pouco eficiente.

$$
\mathrm{OH}^{\cdot}+\mathrm{H}_{2} \mathrm{O}_{2} \rightarrow \mathrm{H}_{2} \mathrm{O}+\mathrm{HO}_{2}^{\cdot} \quad\left(\mathrm{k}_{2}=3,3.10^{7} \mathrm{M}^{-1} \mathrm{~s}^{-1}\right)
$$

A Figura 4 mostra que a temperatura influencia significativamente a concentração residual final do fármaco, que apresentou $C_{O x i, R e s, F i n a l}$ variando de 0,9 a $6,5 \mathrm{mg} / \mathrm{L}$. Observou-se um valor máximo para $T=20^{\circ} \mathrm{C}$, aproximadamente $6,5 \mathrm{mg} / \mathrm{L}$, e valores baixos para 10 e $50^{\circ} \mathrm{C}$, de 1,8 e $0,9 \mathrm{mg} / \mathrm{L}$, respectivamente. Esperava-se que a concentração residual de fármaco diminuísse com o aumento da temperatura, mas não com a diminuição. Estes resultados indicam que com a elevação da temperatura ocorre uma maior degradação do peróxido de hidrogênio e maior produção de radicais hidroxila, e maior ataque às moléculas orgânicas. Acredita-se que a diminuição da concentração residual de oxitetraciclina com a diminuição da temperatura se deva à imprecisão experimental ou erro analítico e serão refeitos futuramente para comprovação. 


\section{9 a 22 de outubro de 2014 \\ Florianópolis/SC}

\section{CONCLUSÕES}

A análise paramétrica mostrou que as variáveis que mais influenciam o processo são, respectivamente, a concentração inicial de peróxido de hidrogênio, $C_{\mathrm{H} 2 \mathrm{O} 2}$, a concentração de ion ferroso, $C_{F e}{ }^{2+}$, e a temperatura. A análise paramétrica mostrou que a concentração inicial de peróxido de hidrogênio e de ion ferroso não influenciam o processo nas faixas de valores 300 a $700 \mathrm{mg} / \mathrm{L}$ e 35 a $120 \mathrm{mg} / \mathrm{L}$, respectivamente. Foi observado um valor máximo de concentração residual de oxitetraciclina para $T=20^{\circ} \mathrm{C}$, o que não é usual e merece mais estudos para buscar por respostas mais adequadas. $\mathrm{O}$ método espectrofotométrico se mostrou adequado para a análise da oxitetraciclina, mas deveria ser validado através de análises em HPLC-MS.

\section{REFERÊNCIAS}

AGA, D.S. Fate of Pharmaceuticals in the Environment and in Water Treatment Systems. CRC Press, 2008.

BILA, D. M.; DEZOTTI, M. Fármacos no meio ambiente. Quím. Nova, v. 24 (4), p. 523-530, 2003.

BORGHI, A. A.; PALMA, M. S. A. Tetracycline: production, waste treatment and environmental impact assessment. Braz. J. Pharm. Sci., v. 50, n. 1, p. 1-16, 2014.

FENT, K; ESCHER, C; CAMINADA, D. Estrogen activity of pharmaceuticals and pharmaceutical mixtures in a yeast reporter gene system. Reprod. Toxicol., v. 22, p. 175 - 185, 2006.

HIRSCH, R; TERNES, T. A.; HABERER, K.; MEHLICH, A.; BALlWANZ, F.; KRATZ, K. L. Determination of antibiotics in different water compartments via liquid chromatographyelectrospray tandem mass spectrometry. J. Chromatogr. A, v. 815, p. 213-223, 1998.

JI, K.; CHOI, K.; LEE, S.; PARK, S.; KHIM, J. S.; JO, E. H.; CHOI, K. H.; ZHANG, X.; GIESY, J. P. Effects of sulfathiazole oxytetracycline and chlortetracycline on steroidogenesis in the human adrenocarcinoma (H295R) cell line and freshwater fish Oryzias latipes. J. Hazard. Mater., v. 182, p. 494-502, 2010.

JI, K.; KIM, S.; HAN, S.; SEO, J.; LEE, S.; PARK, Y.; CHOI, K.; KHO, Y. L.; KIM, P. G.; PARK, J.; CHOI, K. Risk assessment of chlortetracycline, oxytetracycline, sulfamethazine, sulfathiazole, and erythromycin in aquatic environment: are the current environmental concentrations safe? Ecotoxicology, v. 21, p. 2031-2050, 2012.

KÜMMERER, K. Antibiotics in the aquatic environment - A review - Part I. Chemosphere, v. 75, p. 417-434, 2009.

LI, K.; YEDILER, A.; YANG, M.; SCHULTE-HOSTEDE, S.; WONG, M. H. Ozonation of oxytetracycline and toxicological assessment of its oxidation by-products. Chemosphere, v. 72, p. 473-478, 2008.

MARTINS, E.R.; YAMAMOTO, A.C.A.; HAHN, R.C. Diagnóstico Laboratorial em Microbiologia Clínica - Apostila de Bacteriologia - Faculdade de Ciências Farmacêuticas - Universidade de Cuiabá. 2011. Disponível em: <http://pt.scribd.com/doc/51848504/APBac-11>. Acesso em: 30/06/2011.

MIYAGUTI, R. M.; PALMA, M. S. A. Degradação de oxitetraciclina pelo processo oxidativo de Fenton. In: XIX Congresso Brasileiro de Engenharia Química. Búzios, RJ, 9 a 12 de setembro de 2012. 
NEYENS, E.; BAEYENS, J. A review of classic Fenton's peroxidation as an advanced oxidation technique. J. Haz. Mat., v. 98, p. 33-50, 2003.

PARK, S.; CHOI, K. Hazard assessment of commonly used agricultural antibiotics on aquatic ecosystems. Ecotoxicology, v. 17, p. 526-538, 2008.

PIGNATELLO, J. J.; OLIVEROS, E.; MACKAY, A. Advanced oxidation process for organic contaminant destruction based on the Fenton reaction and related chemistry. Critical Reviews in Environ. Sci. Technol., v. 36, n. 1, p. 1-84, 2006.

STANKOV, M.J., VESELINOVIC, D. Spectrophotometric methods for determination of doxycycline in pharmaceutical preparations. Pharmazie, v. 43, n. 1, 49-50, 1988.

WANG, J. L.; XU, L. J. Advanced oxidation process for wastewater treatment: formation of hydroxyl radical and application. Crit. Rev. Environ. Sci. Technol., v. 42, p. 251-325, 2012.

WEI, R.; GE, F.; HUANG, S.; CHEN, M.; WANG, R. Occurrence of veterinary antibiotics in animal wastewater and surface water around farms in Jiangsu Province, China. Chemosphere, v. 82, n. 10, p. 1408-1414, 2010. 